Article

\title{
Optimization of Spiral-Wound Microfiltration Process Parameters for the Production of Micellar Casein Concentrate
}

\author{
Chenchaiah Marella ${ }^{1,2, *}$, Venkateswarlu Sunkesula ${ }^{1,2} \mathbb{D}$, Ahmed R. A. Hammam ${ }^{1}\left(\mathbb{D}\right.$, Anil Kommineni ${ }^{1}$ and \\ Lloyd E. Metzger 1 \\ 1 Midwest Dairy Foods Research Center, Dairy and Food Science Department, South Dakota State University, \\ Brookings, SD 57007, USA; vsunkesula@idahomilk.us (V.S.); ahmed.hammam@sdstate.edu (A.R.A.H.); \\ anil.kommineni@danone.com (A.K.); Lloyd.Metzger@sdstate.edu (L.E.M.) \\ 2 Idaho Milk Products, Jerome, ID 83338, USA \\ * Correspondence: cmarella@idahomilk.us; Tel.: +1-(208)-324-6572
}

Citation: Marella, C.; Sunkesula, V.; Hammam, A.R.A.; Kommineni, A.; Metzger, L.E. Optimization of Spiral-Wound Microfiltration Process Parameters for the Production of Micellar Casein Concentrate. Membranes 2021, 11, 656. https://doi.org/10.3390/ membranes 11090656

Academic Editors:

Mohtada Sadrzadeh, Anthony

G. Dixon, Laurent Bazinet,

Soryong Chae and Milad

Rabbani Esfahani

Received: 20 July 2021

Accepted: 21 August 2021

Published: 26 August 2021

Publisher's Note: MDPI stays neutral with regard to jurisdictional claims in published maps and institutional affiliations.

Abstract: A systematic selection of different transmembrane pressures (TMP) and levels of diafiltration (DF) was studied to optimize these critical process parameters during the manufacturing of micellar casein concentrate (MCC) using spiral-wound polymeric membrane filtration. Three TMPs $(34.5,62.1$, and $103.4 \mathrm{kPa})$ and four DF levels $(0,70,100$, and $150 \%)$ were applied in the study. The effect of the TMP and DF level on flux rates, serum protein (SP) removal, the casein-to-total-protein ratio, the casein-to-true-protein ratio, and the rejection of casein and SP were evaluated. At all transmembrane pressures, the overall flux increased with increases in the DF level. The impact of DF on the overall flux was more pronounced at lower pressures than at higher pressures. With controlled DF, the instantaneous flux was maintained within $80 \%$ of the initial flux for the entire process run. The combination of $34.5 \mathrm{kPa}$ and a DF level of $150 \%$ resulted in $81.45 \% \mathrm{SP}$ removal, and a casein-to-true-protein ratio of 0.96 . SP removal data from the lab-scale experiments were fitted into a mathematical model using DF levels and the square of TMPs as factors. The model developed in this study could predict SP removal within $90-95 \%$ of actual SP removal achieved from the pilot plant experiments.

Keywords: polymeric spiral-wound membrane; microfiltration; transmembrane pressure; diafiltration; micellar casein concentrate

\section{Introduction}

Membrane separation technology was introduced to dairy processing in the early 1970s as an alternative to some thermal and non-thermal processes [1]. Commonly used membrane processes in the dairy industry are microfiltration (MF), ultrafiltration (UF), nanofiltration (NF), and reverse osmosis (RO). The MF process uses porous membranes with a porosity of 0.1 to $2 \mu \mathrm{m}$ [2] and is extensively used in the defatting of whey stream in the production of whey protein isolates [3]. The interest in using MF in micellar casein concentrate (MCC) production has increased recently [4-8]. The MCC is produced from the MF of skim milk by permeating most of the serum protein (SP) and non-protein nitrogen components, thereby increasing the ratio of casein to total protein $(\mathrm{CN} / \mathrm{TKN})$ and casein to true protein (CN/TP). The retentate obtained from this process is a concentrated colloidal suspension [9] containing casein in micellar form, lactose, minerals, and some serum proteins. MCC has been utilized in some applications, such as cheese making $[7,10,11]$, acid curd [12], process cheese [7,13-16], imitation mozzarella cheese [17], and Greek-style yogurt $[7,18]$. MCC has other promising applications, such as nutritional meal replacements, whipped toppings, and coffee whiteners. The permeate obtained from this process is another ideal starting material for manufacturing native serum protein concentrates, native $\alpha$-lactalbumin, and $\beta$-lactoglobulin-enriched protein ingredients. 
Most of the research on the MF of skim milk for MCC production has used ceramic MF membranes $[6,8,19,20]$. Ceramic membrane systems are capital intensive, and membrane replacements are expensive $[7,21,22]$. Compared to these systems, membrane separation systems using polymeric membranes have a smaller footprint, are inexpensive, and are familiar to most of the US dairy processors. In recent years, the interest in assessing the suitability and efficiency of polymeric MF membranes for MCC production has been increased [5,7,21,23-27]. It has been shown that using ceramic membranes, over $95 \%$ of serum protein could be removed in a three-stage process in which diafiltration (DF) to a level of $200 \%$ (on the basis of feed volume) was used. DF is a process in which water is added to the retentate during MF and further concentration is carried out. This step is intended to improve the serum protein (SP) removal and to control the membrane polarization phenomenon $[7,28]$. Studies conducted on the use of polymeric membranes for the production of MCC have shown that approximately $40 \%$ of SP is removed from skim milk at the first stage of MF $[5,21]$ and the cumulative SP removal increases to around $60 \%$ in the second stage, when $200 \%$ of DF water is added to the retentate of the first stage [5]. In this process, skim milk is concentrated to three times (3X) volume reduction (VR) and water equal to the original milk volume is added to the retentate. Further filtration is done to a VR of $3 X$, and this process is repeated twice, totaling $200 \%$ DF. While this shows the positive impact of DF on process efficiency, it is essential to retain the membrane permeation characteristics over extended process runs to maximize the SP removal. During the MF of skim milk, concentrations of materials retained by the membrane continue to increase with process time. Higher concentrations of these materials in the bulk of the fluid lead to a more pronounced concentration-polarization of the membrane or fouling, thereby negatively impacting the serum protein permeation through the membrane $[7,28]$. This effect could be seen when only $40 \%$ of SP could be removed during MF without adding DF water, and this percentage could be increased to $70 \%$ with DF water. When DF water is added to the retentate, the bulk concentration of material goes down, thereby improving the membrane permeation characteristics. A controlled DF addition should help minimize the concentration-polarization effect and maximize SP removal in this process.

Besides DF, transmembrane pressure (TMP) is also an important operating variable in the MF process. TMP is the driving force in the MF process and is the most pressuresensitive of all the membrane processes. Using higher pressure leads to higher initial flux rates but causes increased concentration polarization or fouling, leading to a gradual decrease in flux rates and membrane permeation characteristics [28]. The formation of a polarization layer and subsequent compaction of this layer and the membrane at higher pressures lead to the pressure-independent operation of MF. Therefore, to sustain a reasonable flux rate over a longer process run and to maintain membrane permeation characteristics, the selection of suitable TMP is very important.

Thus, the objective of the present study is to evaluate the spiral-wound (SW) MF process for maximizing SP removal by optimizing the operating pressure and the DF level.

\section{Materials and Methods}

\subsection{Feed}

Fresh skim milk was collected from the South Dakota State University dairy plant. The skim milk was pasteurized at $63^{\circ} \mathrm{C}$ for $30 \mathrm{~min}$. For different replications, skim milk collected on different days was utilized.

\subsection{Membranes}

Polyvinylidene fluoride (PVDF) membranes in a flat sheet configuration (Parker Process Advanced Filtration Division, Oxnard, CA, USA) were used in the lab-scale MF experiments. The membrane sheets were cut to the required size of $14.0 \mathrm{~cm} \times 15.2 \mathrm{~cm}$ for use in an OPTISEP membrane unit. Before using, all the flat sheet membranes were kept wet with $1 \%$ sodium metabisulfite solution and stored at $5{ }^{\circ} \mathrm{C}$. For pilot plant experiments, two $0.5 \mu \mathrm{m}$ PVDF membranes in SW configuration connected in parallel were used (element 
model FH 3030-OS03S). Each element was $97 \mathrm{~mm}$ in diameter and $762 \mathrm{~mm}$ in length. The elements had $1.1 \mathrm{~mm}$ spacers with a membrane area of $4.3 \mathrm{~m}^{2}$ per element.

\subsection{Proximate Analysis}

Samples of feed, permeate, and retentate were analyzed for total solids (TS) using direct forced-air oven drying [29] (AOAC, 2000; method 990.20). Total protein nitrogen $(\mathrm{TKN})$, noncasein nitrogen $(\mathrm{NCN})$ and non-protein nitrogen (NPN) were determined by the block digester method using a micro-Kjeldahl apparatus. The true protein (TP) was calculated as the difference between TKN and NPN. Casein (CN) was calculated as the difference between TKN and NCN. The SP content was calculated as the difference between NCN and NPN. A multiplication factor of 6.38 was used to convert nitrogen to protein.

\subsection{SP Removal}

The SP removal was calculated using micro-Kjeldahl data and the quantities of skim milk used and permeate collected from the process. The SP removal (\%) was calculated by dividing the SP content of permeate $(\mathrm{g})$ by the SP content $(\mathrm{g})$ of the original skim milk and multiplying by 100 .

\subsection{Overall Flux}

Overall flux (O flux) was calculated as permeate flow rate per unit filtration area per unit time and is expressed as liters per meter square per hour (LMH).

$$
\text { Overall flux, } \mathrm{LMH}=\frac{\text { Permeate flow }[\mathrm{mL}] \times 60}{\text { Collection time }[\mathrm{min}] \times \text { Area of membrane }\left[\mathrm{m}^{2}\right] \times 1000}
$$

In the present study, $\mathrm{O}$ flux was averaged over the entire process time. The feed volume and VR used in the study resulted in a process time of about 2 to $6 \mathrm{~h}$.

\subsection{Rejection Coefficients for $S P$ and $C N$}

Classical rejection coefficients are generally calculated as the ratio of concentration (C) of any component in permeate $(\mathrm{p})$ and retentate $(\mathrm{r})$. With processes using DF water, the concentration of any component in the permeate goes down due to the dilution effect. This gives a negative rejection coefficient for that component. To overcome this situation, in the present study rejection coefficients were calculated differently. The pore size of the membrane used in the experiments was $0.5 \mu$. Theoretically, all the components present in the milk should pass through the membrane resulting in 0 rejections [28]. This corresponds to an equal concentration of the component both in permeate and retentate. In the present study, rejection of a component is expressed as:

$$
\operatorname{Rej}=1-\frac{C p}{C f}
$$

where $\mathrm{Cp}$ is the concentration of any component in the permeate while $\mathrm{Cf}$ is the concentration of the component in the feed after adjusting for the level of DF water. For example, if skim milk had $0.54 \%$ serum protein and if an experimental run used $100 \%$ diafiltration, the adjusted concentration of serum protein in feed (Cf) would be $0.54 / 2=0.27 \%$.

\subsection{Operating Variables}

Transmembrane pressure (TMP) is the driving force in the MF of skim milk. As discussed in the preceding sections, the magnitude of TMP affects the nature of the pseudo filtration layer (concentration-polarization layer) formed on the membrane surface. A higher TMP leads to more compaction of this layer, which impacts the membrane permeation characteristics. To study the effect of TMP, experiments were conducted at three levels of TMP $(34.5,62.1$, and $103.4 \mathrm{kPa})$. The TMP was read using an Ashcroft industrial Duralife pressure gauge with a measuring range of $0-413.7 \mathrm{kPa}$. 
TMP is the difference between the average of inlet and outlet pressures minus the permeate pressure.

$$
\mathrm{TMP}=\frac{\mathrm{P}_{\text {in }}+\mathrm{P}_{\text {out }}}{2}-\mathrm{P}_{\mathrm{p}}
$$

Diafiltration (DF) is often used in the MF process to maximize the protein recovery in the defatting of whey streams and in the MF of skim milk to maximize the SP removal, so that the $\mathrm{CN}$ to TP ratio in MCC can be increased. In the present study, three levels of DF $(70,100$, and $150 \%$, based on the feed volume) were used. A control run without any DF was also used to compare the effectiveness of DF in improving the efficiency of the MF process.

\subsection{Experimental Procedure}

Lab-scale studies: MF experiments were conducted using a lab-scale plate-and-frame unit (OPTISEP 400-unit part \# 20-000-1000) procured from NCSRT, NC. The unit used flat sheet membranes of $14 \mathrm{~cm} \times 15.2 \mathrm{~cm}$ size with a filtration area of $0.02 \mathrm{~m}^{2}$. The gasket provided a channel height of $0.5 \mathrm{~mm}$ for the feed channel. The TMP was measured using the Ashcroft industrial Duralife pressure gauge (Ascroft, Stratford, CT06614, measuring range of $0-413.7 \mathrm{kPa}$ ) fitted to the end plate. The pressure was varied by controlling the back-pressure valve provided on the retentate line at the outlet of the unit. A variable-speed peristaltic pump (Masterflex peristaltic pump, Cat. \# EW-77521-40, Cole Parmer, IL, USA) coupled to a standard L/S pump head (Cat \# C-07024-21) was used to supply the feed to the membrane unit. The feed flow rate to the membrane unit was maintained at $1.7 \mathrm{~L} / \mathrm{min}$. Flat sheet membranes were cut into $14 \mathrm{~cm} \times 15.2 \mathrm{~cm}$ pieces and were assembled in the filtration unit as per the instruction manual supplied with the filtration unit. Before each run, the membrane was flushed with $6 \mathrm{~L}$ of deionized water to flush out the storage solvent. Each batch was begun with a feed volume of $800 \mathrm{~mL}$, and separation was conducted on continuous concentration mode as shown in Figure 1, to a final retentate volume of $200 \mathrm{~mL}$, giving a VR of 4 . All the experiments were conducted at a temperature of $24^{\circ} \mathrm{C}$ and a pH of 6.6.

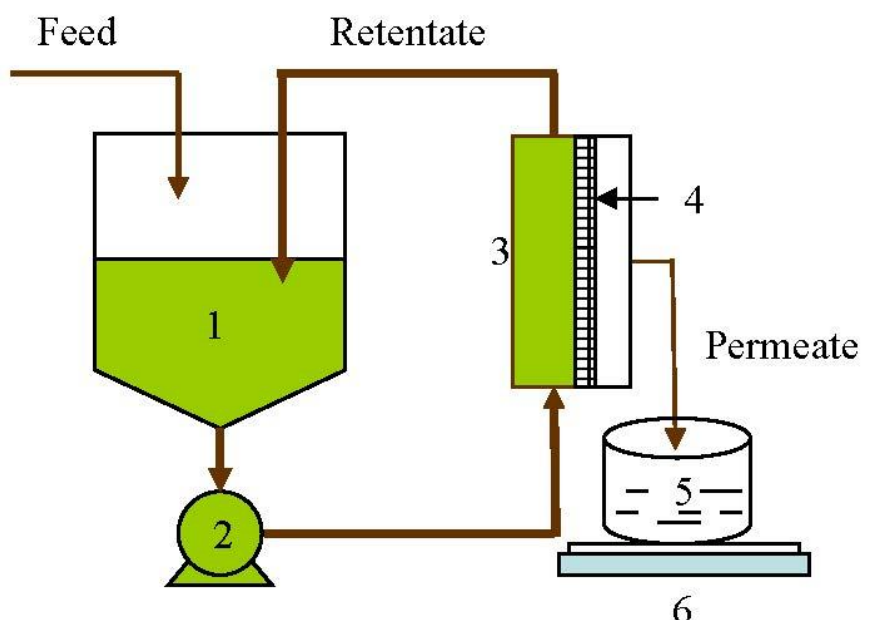

Figure 1. Schematic diagram of the lab-scale membrane separation process. 1-Feed tank; 2-Pump; 3-Flat sheet unit; 4-Membrane; 5-Permeate collection tank; 6-Weighing balance.

\subsection{Statistical Analysis}

All the data were analyzed with one-way ANOVA to test for significant differences among the treatments, with a type I error rate $(\alpha)$ of 0.05 , using MINITAB $^{\circledR} 19$ (Minitab, LLC, Chicago, IL, USA). 


\section{Results and Discussion}

3.1. Flux

The data on O flux obtained at all levels of DF and for all the pressures used in the study are presented in Figure 2. Both TMP and DF used in the study had a significant effect on $\mathrm{O}$ flux. This observation is similar to the results reported by Salunke and others [3]. The highest $\mathrm{O}$ flux of $23.61 \mathrm{LMH}$ was obtained at the lowest TMP used in the study. As the TMP increased, O flux decreased. However, the O flux obtained at 34.5 and $62.1 \mathrm{kPa}$ TMP (23.61 and $21.1 \mathrm{LMH}$, respectively) was statistically not different $(p>0.05)$. It has been reported that the use of $50 \mathrm{kPa}$ TMP while manufacturing casein concentrate utilizing polymeric membranes did not affect the flux significantly [24], which is similar to the results obtained in this study. As shown in Figure 2, addition of DF water had a positive impact on the O flux. O flux increased by $50 \%$ from 0 to $70 \%$ DF at $34.5 \mathrm{kPa}$ TMP, while the increase at the same TMP was about $100 \%$ from 0 to $150 \%$ DF. For the control run $(0 \% \mathrm{DF})$, there was no significant difference observed in $\mathrm{O}$ flux for all the pressures used in the study and was about $14.75 \pm 0.30 \mathrm{LMH}$. This shows that, it is essential to select appropriate pressure and DF level for optimum performance of MF. From the data presented, it is also clear that at higher operating pressures, DF becomes less effective in influencing the process flux rates. The lowest flux rates obtained in control runs at all the three pressures may be because, as higher concentrations of rejected solids build up in the retentate, the polarization of membrane becomes more pronounced and dictates the permeation characteristics of the membrane, making the process operate in a pressure-independent region [3,7]. DF showed a considerable influence on the process flux rates, especially at the lower pressures used in the study. It was reported that the DF water increased the flux in stage three as compared to stage one of MF [5].

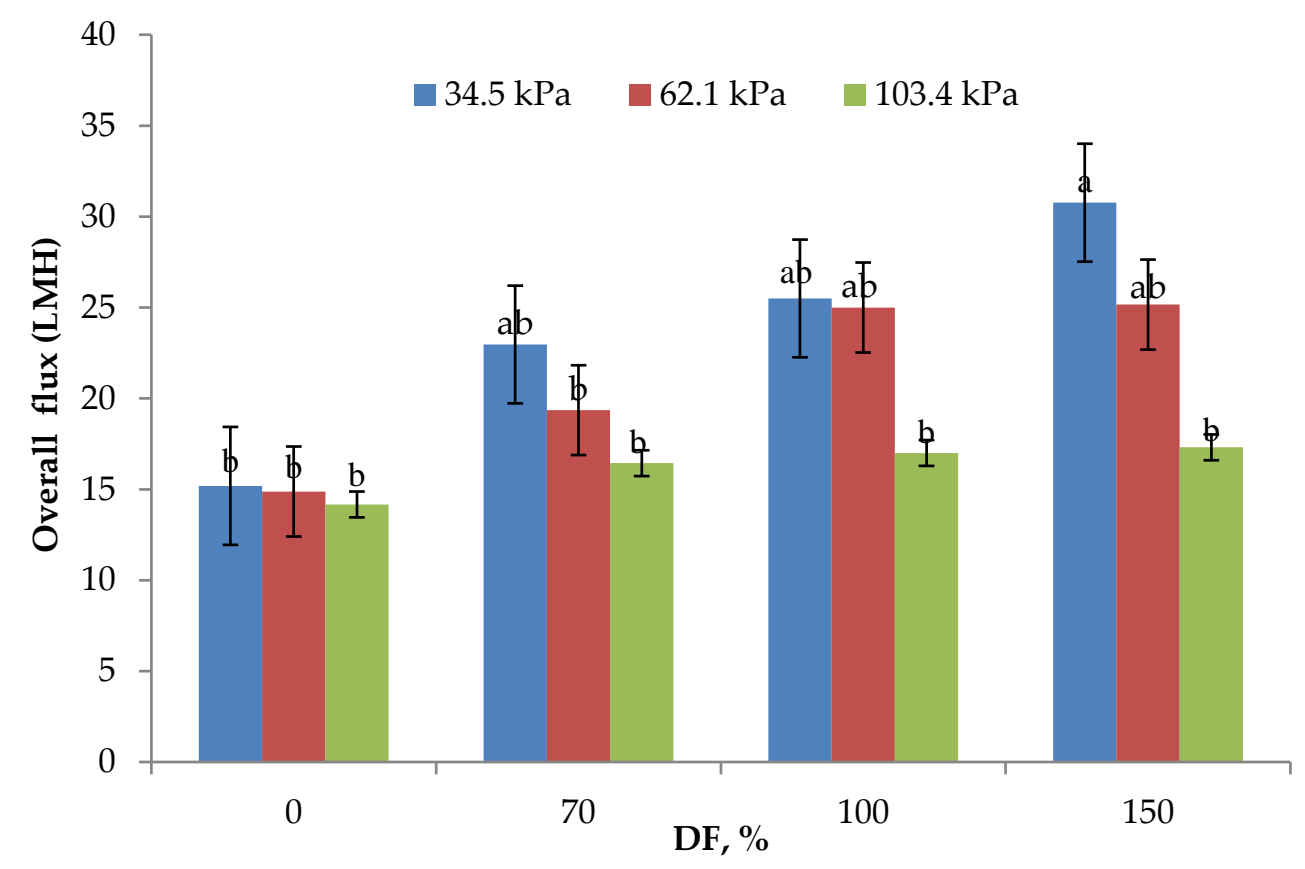

Figure 2. Overall flux means $(n=3)$ obtained from the lab-scale studies. All experiments were conducted at $24^{\circ} \mathrm{C}$ and $800 \mathrm{~mL}$ feed was concentrated to a final volume of $200 \mathrm{~mL}$ resulting in a fourfold volume reduction (VR). DF is diafiltration water added, measured as a percentage of original feed volume. ${ }^{a}, \mathrm{~b}$ Means not sharing the same letter are significantly different $(p<0.05)$.

Instantaneous flux rates obtained during the lab-scale run for $34.5 \mathrm{kPa}$ pressure at all DF levels are presented in Figure 3. From the data presented in Figure 3, in the case of the control run the flux values continued to drop over the entire process run-duration of about $2 \mathrm{~h}$. Zulewska et al. reported that the flux of the SW system decreased with increasing 
processing time [21]. This was also similar to Beckman's study, which found that flux is decreased during three-stage MF processing [5]. For the other runs, DF water was added at a VR of $1.23,1.45,1.68,1.88,1.88$, and 2.67. After the final addition at a VR of 2.67, the product was concentrated until a VR of 4 was reached. The valleys and peaks in the flux graphs are due to addition of DF water at different intervals. For control run, the initial flux was about 19.5 LMH; by the end of 3 VR (a concentration factor of three), the flux was only $60 \%$ of the initial flux. For all the DF runs, the flux at 3 VR was about $78-80 \%$ of the initial flux. The drop in flux from its initial value after about $90-95 \%$ of the process run-time was roughly $5-10 \%$. The addition of DF in small quantities over several intervals of the process run helped sustain the process flux rate for a longer time. Additionally, the level of DF had a strong effect on the flux rates, resulting in higher flux rates with higher DF level.

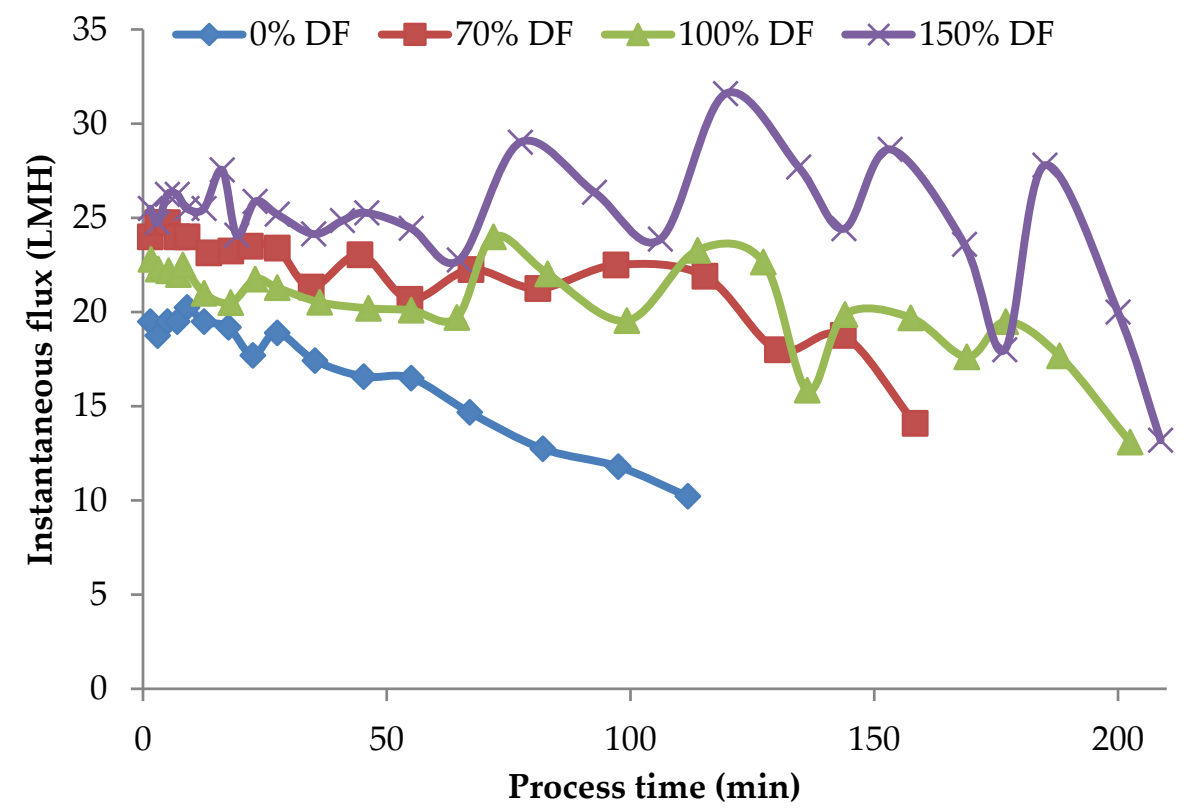

Figure 3. Instantaneous flux obtained from the lab-scale studies at $34.5 \mathrm{kPa}$ pressure. Instantaneous fluxes are arrived at by measuring the permeate at various time intervals over the entire process run and averaging for that time interval. All the experiments were conducted at $24{ }^{\circ} \mathrm{C}$ and $800 \mathrm{~mL}$ feed was concentrated to a final volume of $200 \mathrm{~mL}$ resulting in a volume reduction of 4 (VR). DF is the percentage of diafiltration water based on the original feed volume.

Data presented in Figure 4 shows the impact of operating pressure on flux rates. From the data presented, the operating pressure showed a strong impact on the flux. The flux at all time intervals was about $50 \%$ higher for process runs that used $34.5 \mathrm{kPa}$ pressure when compared to the run that used $103.4 \mathrm{kPa}$ pressure. As highlighted in the earlier sections, MF is a pressure-sensitive process. Higher pressures promote a more pronounced polarization of the membrane. Furthermore, there is a compaction of this layer and the membrane leading to reduced flux. In the $103.4 \mathrm{kPa}$ case, these phenomena may be overshadowing the advantage of DF, thereby maintaining the difference in flux among the three pressures used in the study. 


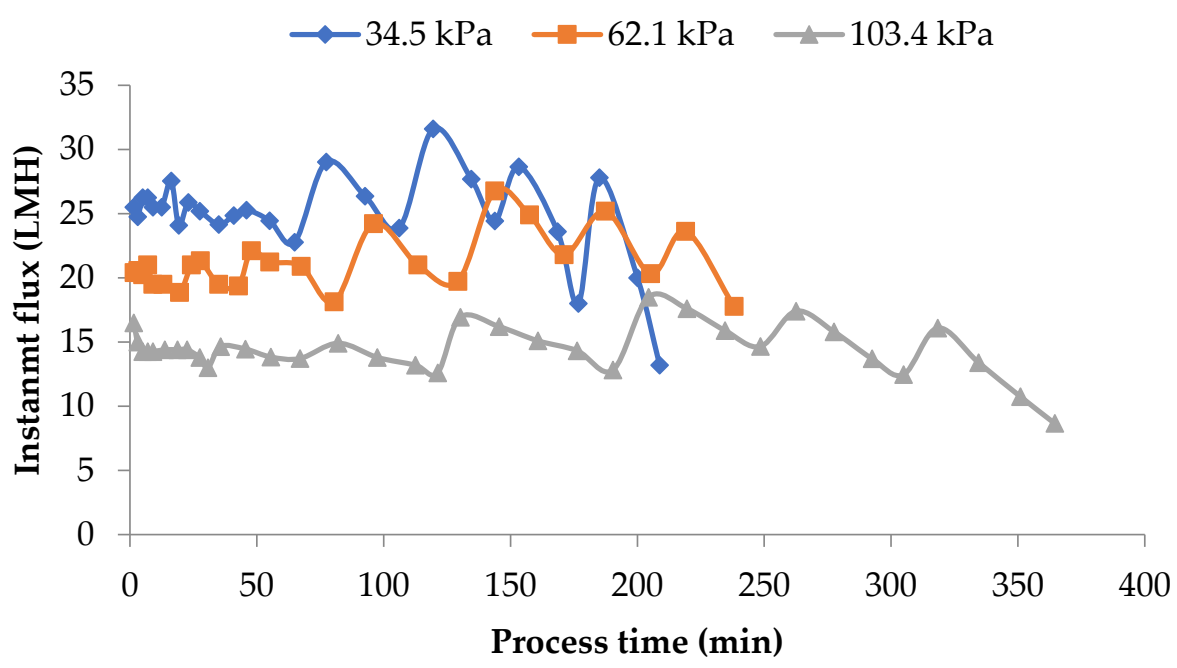

Figure 4. Instantaneous flux obtained from the lab-scale studies at the three pressures used. Diafiltration was $150 \%$ of feed volume and was added at 6 intervals. Instantaneous fluxes are arrived at by measuring the permeate at various time intervals over the entire process run and averaging for that time interval. All the experiments were conducted at $24{ }^{\circ} \mathrm{C}$ and $800 \mathrm{~mL}$ feed was concentrated to a final volume of $200 \mathrm{~mL}$ resulting in a volume reduction of 4 (VR). DF is the percentage of diafiltration based on the original feed volume.

\subsection{SP Removal}

Serum protein removal data from the experiments are presented in Figure 5. Without $\mathrm{DF}$, SP removal ranged from 35 to $50 \%$, the highest being for $34.5 \mathrm{kPa}$ and the lowest being for $106.4 \mathrm{kPa}$ pressure. The statistical analysis of data showed that the SP removal obtained at 34.5 and $62.1 \mathrm{kPa}$ TMP at 0,70 , and 100\% DF were not statistically different $(p>0.05)$. At all the levels of DF, SP removal decreased with increases in the operating pressure. As discussed in the preceding sections, concentration polarization and compaction of the polarized layer, as well as the membrane, may determine the membrane permeation characteristics $[23,30]$ and mask the beneficial effect of DF at higher operating pressures. The use of $70 \% \mathrm{DF}$ at $34.5 \mathrm{kPa}$ gave the same SP removal rate as that of $100 \% \mathrm{DF}$ at $62.1 \mathrm{kPa}$ pressure. Additionally, $100 \% \mathrm{DF}$ at $34.5 \mathrm{kPa}$ pressure gave a similar SP removal rate as compared to $150 \% \mathrm{DF}$ at $62.1 \mathrm{kPa}$ pressure. The highest SP removal of $81.45 \%$ was obtained with the use of $34.5 \mathrm{kPa}$ pressure and $150 \% \mathrm{DF}$. These results highlight the importance of the selection of an appropriate operating pressure and level of DF for maximizing SP removal. A similar trend was found by Hurt and Barbano when studying the processing conditions of MF to remove SP [28]. They reported that increasing the DF and CF $5 \times$ led to an elevation of SP removal from 88.66 to $99.47 \%$.

The SP removal data obtained from the lab-scale runs were fitted into a mathematical model and expressed as a function of the DF level and the square of TMP.

$$
\mathrm{SP} \mathrm{R} \%=58.705-0.0015 \times \mathrm{TMP} 2+0.18 \times \mathrm{DF}
$$

where TMP is in $\mathrm{kPa}$ and DF is \% of water added based on feed volume. Using the model, it is possible to predict SP removal at any selected operating condition. 


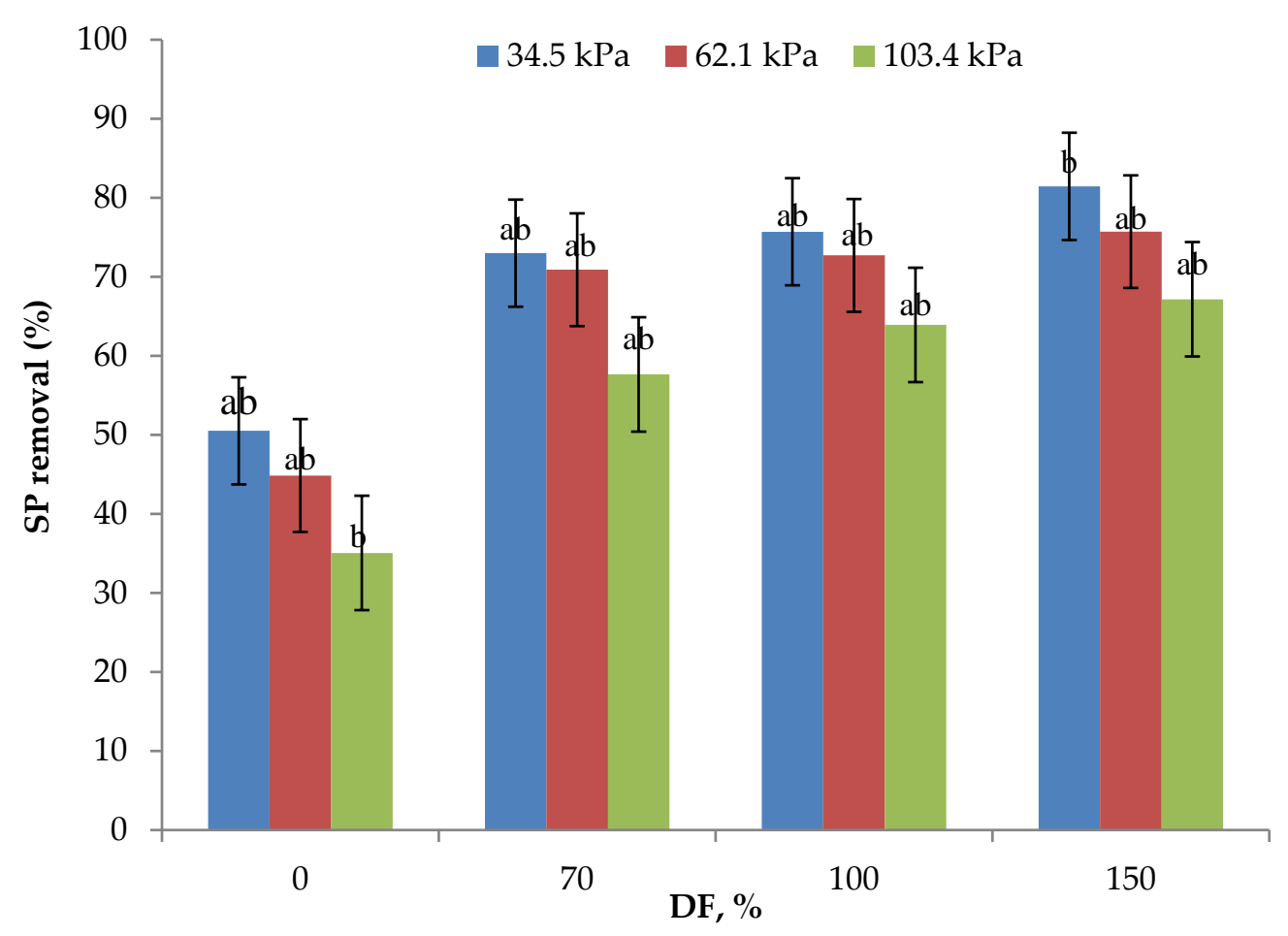

Figure 5. Data on serum protein (SP) removal obtained from the lab-scale studies at three pressures and for all levels of diafiltration used. Diafiltration (DF) water was on the basis of feed volume and was added at 6 intervals during the process. All the experiments were conducted at $24{ }^{\circ} \mathrm{C}$ and $800 \mathrm{~mL}$ feed was concentrated to a final volume of $200 \mathrm{~mL}$ resulting in a volume reduction of 4 (VR). ${ }^{a, b}$ Means not sharing the same letter are significantly different $(p<0.05)$.

\subsection{Rejection of $S P$ and $C N$}

The data on CN/TKN, CN/TP ratios, rejection of CN (rej CN) and SP (rej SP) are presented in Table 1. In skim milk, the CN/TKN and CN/TP ratios were 0.77-0.79 and $0.8-0.83$, respectively. The CN/TKN ratio ranged from 0.87 to 0.96 ; the highest ratio of 0.96 was obtained with $34.5 \mathrm{kPa}$ pressure and $150 \% \mathrm{DF}$. The $\mathrm{CN} / \mathrm{TP}$ ratio ranged from 0.89 to 0.96 , the highest ratio of 0.96 was obtained with the use of $34.5 \mathrm{kPa}$ TMP and $150 \%$ DF. For this combination, the highest SP removal was obtained. From the data, rej SP increased with operating pressure and decreased with the level of DF. The lowest rej SP of 0.1 was obtained with $34.5 \mathrm{kPa}$ TMP and $150 \%$ DF combination. For all the runs, rej $\mathrm{CN}$ ranged from 0.97 to 1.0 by the membrane. The casein content of permeates ranged from 0.01 to $0.04 \%$. The high rejection of SP could have resulted from fouling on the membrane, which has more effect with a lower DF level [28]. Beckman and others found that high TMP led to a higher SP rejection [5,23], which we noticed at all DF levels.

\subsection{Pilot-Scale Experiments}

Pilot-scale experiments were conducted with $151.4 \mathrm{~L}$ of fresh skim milk for each experiment (Figure 6). A batch type pilot MF unit fitted with two SW (3830) PVDF membrane elements was used for the MF of skim milk. Five pilot experiments were conducted at a $34.5 \mathrm{kPa}$ baseline and $103.4 \mathrm{kPa}$ differential pressures, resulting in a TMP of $86.2 \mathrm{kPa}(12.5 \mathrm{psi})$. These five runs used $100 \% \mathrm{DF}$. Two experiments were conducted at the same pressures, but with $150 \%$ DF. Experiments were also conducted at a $62.1 \mathrm{kPa}$ baseline and $103.4 \mathrm{kPa}$ differential pressures, using 70 and $100 \% \mathrm{DF}$. All the experiments were conducted in continuous concentration mode, concentrating the feed to a final volume of $37.85 \mathrm{~L}$ giving a VR of 4 . All the experiments were conducted at $24^{\circ} \mathrm{C}$. Deionized water was used for DF purposes. 
Table 1. Mean $(n=3)$ data on casein-to-total-protein ratio $(\mathrm{CN} / \mathrm{TKN})$, casein-to-true-protein ratio $(\mathrm{CN} / \mathrm{TP})$, rejection of casein $(\operatorname{Rej} C N)$ and of serum protein (Rej SP) obtained from the lab-scale experiments.

\begin{tabular}{|c|c|c|c|c|c|c|c|c|c|c|c|c|}
\hline $\begin{array}{l}\mathrm{DF}^{1} \\
(\%)\end{array}$ & & 0 & & & 70 & & & 100 & & & 150 & \\
\hline $\begin{array}{c}\text { TMP }^{2} \\
\text { (kPa) }\end{array}$ & 34.5 & 62.1 & 103.4 & 34.5 & 62.1 & 103.4 & 34.5 & 62.1 & 103.4 & 34.5 & 62.1 & 103.4 \\
\hline CN/TKN & $0.89 \mathrm{~g}$ & $0.89 \mathrm{~g}$ & $0.87^{\mathrm{h}}$ & $0.94^{b}$ & $0.93^{c}$ & $0.9^{f}$ & $0.94^{\mathrm{b}}$ & $0.93^{c, d, e}$ & $0.92^{\mathrm{e}}$ & $0.96^{\mathrm{a}}$ & $0.95^{\mathrm{b}}$ & $0.93^{c, d, e}$ \\
\hline $\mathrm{CN} / \mathrm{TP}$ & $0.90^{f}$ & $0.90^{f}$ & $0.89^{g}$ & $0.94^{b, c}$ & $0.94^{b, c}$ & $0.92^{\mathrm{e}}$ & $0.95^{\mathrm{b}}$ & $0.95^{\mathrm{b}}$ & $0.93^{c, d}$ & $0.96^{\mathrm{a}}$ & $0.95^{\mathrm{b}}$ & $0.93^{c, d}$ \\
\hline Rej CN & $1.00^{\mathrm{a}}$ & $0.98^{a, b, c}$ & $0.99^{a, b}$ & $0.98^{a, b, c}$ & $0.99^{a, b}$ & $0.99^{a, b}$ & $1.00^{\mathrm{a}}$ & $0.98^{a, b, c}$ & $0.97^{b, c}$ & $0.98^{a, b, c}$ & $0.96^{c}$ & $0.97^{b, c}$ \\
\hline Rej SP & $0.33^{c}$ & $0.40^{\mathrm{b}}$ & $0.53^{\mathrm{a}}$ & $0.14^{\mathrm{e}, \mathrm{f}}$ & $0.17^{\mathrm{e}}$ & $0.32^{\mathrm{c}, \mathrm{d}}$ & $0.13^{e, f}$ & $0.17^{\mathrm{e}}$ & $0.27^{c, d}$ & $0.10^{f}$ & $0.16^{\mathrm{e}, \mathrm{f}}$ & $0.25^{\mathrm{d}}$ \\
\hline
\end{tabular}

${ }^{1} \mathrm{DF}=$ diafiltration; ${ }^{2} \mathrm{TMP}=$ transmembrane pressure. ${ }^{\mathrm{a}-\mathrm{h}}$ Mean values within same row not sharing a superscript are significantly different $(p<0.05)$.

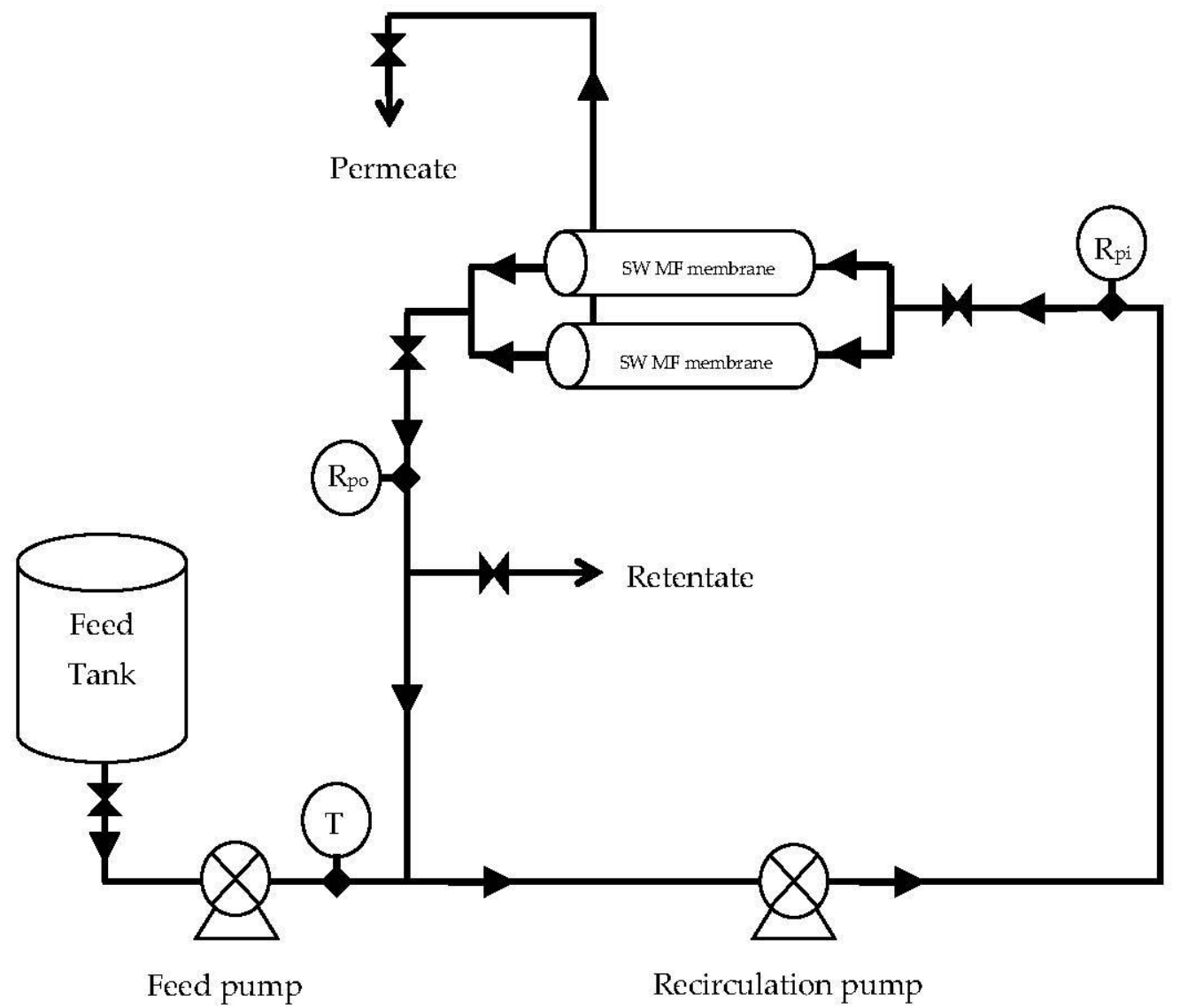

Figure 6. The spiral-wound microfiltration (SW-MF) system used during the microfiltration of skim milk at different pressures and different diafiltration (DF) levels. $\mathrm{T}=$ temperature; $\mathrm{Rpi}=$ retentate pressure inlet; Rpo = retentate pressure outlet.

Using the model developed for lab-scale experiments, SP removal for pilot runs operated under the above-mentioned operating conditions was predicted. Actual SP removal data obtained during the experiments were compared with the predicted values. From the data presented in Table 2, the model predicted SP removal within 90-95\% of the actual values. 
Table 2. Comparison of SP removal predicted by the model and actual SP removal data obtained from the experiments.

\begin{tabular}{|c|c|c|c|c|c|c|c|}
\hline \multirow{2}{*}{ Run \# } & \multicolumn{3}{|c|}{ Operating Pressure, kPa } & \multirow{2}{*}{$\mathrm{DF}^{1}, \%$} & \multicolumn{3}{|c|}{ Serum Protein Removal, \% } \\
\hline & Base & Differential & TMP $^{2}$ & & Actual & Predicted & Difference \\
\hline 1 & 34.5 & 103.4 & 86.2 & 100 & 66.54 & 65.56 & -0.98 \\
\hline 2 & 34.5 & 103.4 & 86.2 & 100 & 68.20 & 65.56 & -2.64 \\
\hline 3 & 34.5 & 103.4 & 86.2 & 100 & 65.46 & 65.56 & 0.10 \\
\hline 4 & 34.5 & 103.4 & 86.2 & 100 & 63.40 & 65.56 & 2.16 \\
\hline 5 & 34.5 & 103.4 & 86.2 & 100 & 63.15 & 65.56 & 2.41 \\
\hline 6 & 34.5 & 103.4 & 86.2 & 150 & 67.86 & 74.56 & 6.70 \\
\hline 7 & 34.5 & 103.4 & 86.2 & 150 & 68.84 & 74.56 & 5.72 \\
\hline 8 & 62.1 & 103.4 & 113.8 & 70 & 53.80 & 51.89 & -1.91 \\
\hline 9 & 62.1 & 103.4 & 113.8 & 70 & 52.70 & 51.89 & -0.81 \\
\hline 10 & 62.1 & 103.4 & 113.8 & 100 & 61.33 & 57.29 & -4.04 \\
\hline
\end{tabular}

${ }^{1} \mathrm{DF}=$ diafiltration; ${ }^{2} \mathrm{TMP}=$ transmembrane pressure.

\subsection{Pilot Plant Process Flux}

In the MF of milk, it is essential to maintain the flux rates reasonably close to the initial flux rates for the selective fractionation of milk components. Any accumulation of a polarization layer on the membrane surface and consequent drop in flux rates is detrimental to the fractionation process. Instantaneous flux rates obtained during pilot-scale runs for $86.2 \mathrm{kPa}$ TMP at 100 and $150 \% \mathrm{DF}$ and for $100 \% \mathrm{DF}$ at $86.2 \mathrm{kPa}$ and $113.8 \mathrm{kPa}$ at $100 \% \mathrm{DF}$ are presented in Figure 7.

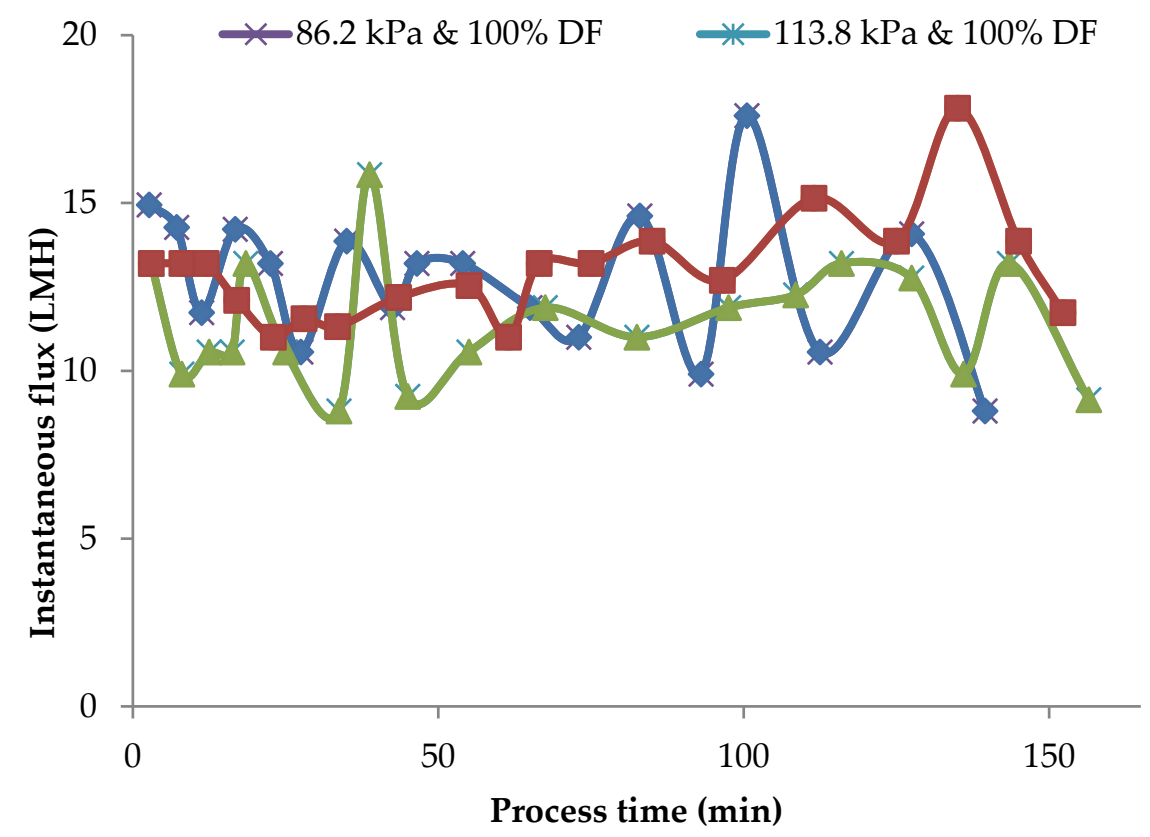

Figure 7. Instantaneous flux obtained for $86.2 \mathrm{kPa}$ TMP at 100 and $150 \% \mathrm{DF}$ and for $113.8 \mathrm{kPa}$ and $100 \%$ DF. The data are from the pilot plant run.

In these runs, DF water was added at VR of 1.23, 1.45, 1.68, 1.88, 1.88, and 2.67. After the final addition at a VR of 2.67, the process was continued to concentrate MCC to a VR of 4 . The valleys and peaks in the flux graphs are due to the addition of DF water at different intervals. The controlled addition of DF water could maintain the flux at or close to initial flux for $80 \%$ of the total process run-time. In these pilot runs, the instantaneous flux was maintained within $90 \%$ of initial flux for about $80 \%$ of the process run. In the case of lab-scale experiments in which no DF was used, instantaneous flux dropped to about $60 \%$ of the initial value (Figure 2) with a consequent drop in flux and impairment of the selective removal of SP. The addition of DF water in small quantities over several intervals 
of the process run sustained the process flux rate for a longer time during the process and helped to maintain membrane selectivity.

\subsection{Rejection of SP and CN-Pilot Runs}

The data on CN/TKN and CN/TP ratios and the rejection of CN and SP are presented in Table 3. From the data, $86.2 \mathrm{kPa}$ TMP had a higher SP removal rate and CN/TKN and $\mathrm{CN} / \mathrm{TP}$ ratios, and a lower rejection of SP. The MF process is a pressure-sensitive process. The results show a definite advantage to operating at lower TMPs. Results also show the effect of the level of DF on SP removal and other parameters, with higher DF levels showing a definite advantage.

Table 3. Mean \pm SD of serum protein removal (SP R, \%), casein-to-total-protein (CN/TKN), casein-to-true-protein (CN/TP) ratio, and rejection of casein $(\operatorname{Rej} C N)$ and serum protein $(\operatorname{Rej} S P)$ data obtained from pilot plant experiments.

\begin{tabular}{|c|c|c|c|c|}
\hline \multirow{2}{*}{$\begin{array}{c}\text { Pressure } \\
\mathrm{DF}^{1}, \%\end{array}$} & \multicolumn{2}{|c|}{ 34.5 Base/86.5 kPa TMP ${ }^{2}$} & \multicolumn{2}{|c|}{ 62.1 Base/113.8 kPa TMP ${ }^{2}$} \\
\hline & 100 & 150 & 70 & 100 \\
\hline Item & Mean $\pm \operatorname{SD}(n=5)$ & Mean $\pm \operatorname{SD}(n=3)$ & Mean $\pm \operatorname{SD}(n=3)$ & - \\
\hline SP R, \% & $65.4 \pm 2.11$ & $68.4 \pm 0.64$ & $53.3 \pm 0.78$ & 61.3 \\
\hline $\mathrm{CN} / \mathrm{TNK}$ & $0.92 \pm 0.01$ & $0.92 \pm 0.00$ & $0.90 \pm 0.01$ & 0.91 \\
\hline $\mathrm{CN} / \mathrm{TP}$ & $0.92 \pm 0.01$ & $0.93 \pm 0.01$ & $0.90 \pm 0.00$ & 0.92 \\
\hline Rej CN & $0.98 \pm 0.00$ & $0.99 \pm 0.01$ & $0.99 \pm 0.00$ & 0.98 \\
\hline Rej SP & $0.27 \pm 0.02$ & $0.27 \pm 0.01$ & $0.38 \pm 0.01$ & 0.30 \\
\hline
\end{tabular}

${ }^{1} \mathrm{DF}=$ diafiltration; ${ }^{2} \mathrm{TMP}=$ transmembrane pressure.

\section{Conclusions}

From the above-presented results, the use of DF positively affected process flux rates and the SP removal rate. Of the various DF levels used in the study, $150 \%$ DF resulted in the highest impact on the MF of skim milk. Over the range of operating pressures used in the study, the use of lower pressures resulted in higher SP removal and process flux rates. This study shows that the use of lower pressures and controlled degrees of DF (the addition of DF water at several intervals) results in maximized SP removal and process flux rates.

Author Contributions: Conceptualization, C.M. and L.E.M.; methodology, C.M. and L.E.M.; software, C.M., V.S., A.R.A.H., A.K. and L.E.M.; validation, C.M., V.S., A.R.A.H., A.K. and L.E.M.; formal analysis, C.M., V.S., A.K. and L.E.M.; investigation, C.M., V.S., A.R.A.H., A.K. and L.E.M.; resources, C.M., V.S., A.R.A.H., A.K. and L.E.M.; data curation, C.M., V.S., A.R.A.H., A.K. and L.E.M.; writing-original draft preparation, C.M., V.S., A.R.A.H., A.K. and L.E.M.; writing-review and editing, C.M., V.S., A.R.A.H., A.K. and L.E.M.; visualization, C.M., V.S., A.R.A.H., A.K. and L.E.M.; supervision, C.M., V.S., A.R.A.H., A.K. and L.E.M.; project administration, C.M., V.S., A.R.A.H., A.K. and L.E.M.; funding acquisition, C.M. and L.E.M. All authors have read and agreed to the published version of the manuscript.

Funding: This work was financially supported by the Midwest Dairy Foods Research Center (MDFRC), South Dakota State University, Brookings, SD, USA, and the Agricultural Experiment Station (AES), South Dakota State University, Brookings, SD, USA.

Institutional Review Board Statement: Not applicable.

Informed Consent Statement: Not applicable.

Data Availability Statement: Data sharing not applicable.

Acknowledgments: The authors gratefully thank and acknowledge the Midwest Dairy Foods Research Center (MDFRC) and Agricultural Experiment Station (AES) for their financial support.

Conflicts of Interest: The authors declare no conflict of interest. 


\section{References}

1. Trung Le, T.; Cabaltica, A.D.; Mien Bui, V. Membrane separations in dairy processing. J. Food Res. Technol. 2014, 2, 1-14.

2. Fox, P.F.; Kelly, A.L. The caseins. In Proteins in Food Processing; Yada, R.Y., Ed.; Woodhead Publishing: Sawston, UK, 2004; pp. 29-71, ISBN 9781855737235.

3. Salunke, P.; Marella, C.; Metzger, L.E. Microfiltration and Ultrafiltration Process to Produce Micellar Casein and Milk Protein Concentrates with 80\% Crude Protein Content: Partitioning of Various Protein Fractions and Constituents. Dairy 2021, 2, 367-384. [CrossRef]

4. Amelia, I.; Barbano, D.M. Production of an $18 \%$ protein liquid micellar casein concentrate with a long refrigerated shelf life1. J. Dairy Sci. 2013, 96, 3340-3349. [CrossRef]

5. Beckman, S.L.; Zulewska, J.; Newbold, M.; Barbano, D.M. Production efficiency of micellar casein concentrate using polymeric spiral-wound microfiltration membranes. J. Dairy Sci. 2010, 93, 4506-4517. [CrossRef] [PubMed]

6. Hurt, E.; Zulewska, J.; Newbold, M.; Barbano, D.M. Micellar casein concentrate production with a 3X, 3-stage, uniform transmembrane pressure ceramic membrane process at $50{ }^{\circ}$ C. J. Dairy Sci. 2010, 93, 5588-5600. [CrossRef]

7. Hammam, A.R.A.; Martínez-Monteagudo, S.I.; Metzger, L.E. Progress in micellar casein concentrate: Production and applications. Compr. Rev. Food Sci. Food Saf. 2021. [CrossRef]

8. Hammam, A.R.A.; Metzger, L.E. Production and storage stability of liquid micellar casein concentrate. J. Dairy Sci. 2018, 101, 8.

9. Rollema, H.S.; Muir, D.D. Casein and Related Products. In Dairy Powders and Concentrated Products; Wiley-Blackwell: Oxford, UK, 2009; pp. 235-254, ISBN 9781405157643.

10. Amelia, I.; Drake, M.; Nelson, B.; Barbano, D.M. A new method for the production of low-fat Cheddar cheese. J. Dairy Sci. 2013, 96, 4870-4884. [CrossRef]

11. Li, B.; Waldron, D.S.; Tobin, J.T.; Subhir, S.; Kelly, A.L.; McSweeney, P.L.H. Evaluation of production of Cheddar cheese from micellar casein concentrate. Int. Dairy J. 2020, 107, 104711. [CrossRef]

12. Hammam, A.R.A.; Metzger, L.E. Manufacture of culture-based acid curd using micellar casein concentrate. J. Dairy Sci. 2020, 103, 130-131.

13. Salunke, P. Impact of Transglutaminase on the Functionality of Milk Protein Concentrate and Micellar Casein Concentrate; South Dakota State University: Brookings, SD, USA, 2013.

14. Hammam, A.R.A.; Beckman, S.L.; Sunkesula, V.; Metzger, L.E. Effect of storage of high concentrated micellar casein on the functional properties of process cheese. J. Dairy Sci. 2019, 102, 34.

15. Hammam, A.R.A.; Metzger, L.E. Manufacturing of process cheese without emulsifying salt using acid curd. J. Dairy Sci. 2019, 102, 81-82.

16. Metzger, L.E.; Hammam, A. Process for Manufacture of Process Cheese without Emulsifying Salt. U.S. Patent Application 16/793,818, 20 August 2020.

17. Hammam, A.R.A.; Metzger, L.E. Manufacture of imitation Mozzarella cheese without emulsifying salts using acid curd and micellar casein concentrate. J. Dairy Sci. 2020, 103, 179.

18. Bong, D.D.; Moraru, C.I. Use of micellar casein concentrate for Greek-style yogurt manufacturing: Effects on processing and product properties. J. Dairy Sci. 2014, 97, 1259-1269. [CrossRef]

19. Zulewska, J.; Barbano, D.M. The effect of linear velocity and flux on performance of ceramic graded permeability membranes when processing skim milk at $50^{\circ} \mathrm{C}$. J. Dairy Sci. 2014, 97, 2619-2632. [CrossRef]

20. Adams, M.C.; Barbano, D.M. Effect of ceramic membrane channel diameter on limiting retentate protein concentration during skim milk microfiltration1. J. Dairy Sci. 2016, 99, 167-182. [CrossRef] [PubMed]

21. Zulewska, J.; Newbold, M.; Barbano, D.M. Efficiency of serum protein removal from skim milk with ceramic and polymeric membranes at $50{ }^{\circ}$ C. J. Dairy Sci. 2009, 92, 1361-1377. [CrossRef] [PubMed]

22. Hammam, A.R.A. Production and Storage Stability of High Concentrated Micellar Casein and its Effect on the Functional Properties of Process Cheese Products; South Dakota State University: Brookings, SD, USA, 2019.

23. Beckman, S.L.; Barbano, D.M. Effect of microfiltration concentration factor on serum protein removal from skim milk using spiral-wound polymeric membranes1. J. Dairy Sci. 2013, 96, 6199-6212. [CrossRef] [PubMed]

24. Lawrence, N.D.; Kentish, S.E.; O'Connor, A.J.; Barber, A.R.; Stevens, G.W. Microfiltration of skim milk using polymeric membranes for casein concentrate manufacture. Sep. Purif. Technol. 2008, 60, 237-244. [CrossRef]

25. Govindasamy-Lucey, S.; Jaeggi, J.J.; Johnson, M.E.; Wang, T.; Lucey, J.A. Use of Cold Microfiltration Retentates Produced with Polymeric Membranes for Standardization of Milks for Manufacture of Pizza Cheese. J. Dairy Sci. 2007, 90, 4552-4568. [CrossRef]

26. Marella, C.; Salunke, P.; Metzger, L.E. Optimization of spiral wound microfiltration process production of micellar casein concentrate. J. Dairy Sci. 2011, 94. [CrossRef]

27. Carter, B.G.; Cheng, N.; Kapoor, R.; Meletharayil, G.H.; Drake, M.A. Invited review: Microfiltration-derived casein and whey proteins from milk. J. Dairy Sci. 2021. [CrossRef] [PubMed]

28. Hurt, E.; Barbano, D.M. Processing factors that influence casein and serum protein separation by microfiltration1. J. Dairy Sci. 2010, 93, 4928-4941. [CrossRef]

29. AOAC International. AOAC Official Methods of Analysis, 17th ed.; AOAC International: Gaithersburg, MD, USA, 2000.

30. Hartinger, M.; Heidebrecht, H.-J.; Schiffer, S.; Dumpler, J.; Kulozik, U. Milk Protein Fractionation by Means of Spiral-Wound Microfiltration Membranes: Effect of the Pressure Adjustment Mode and Temperature on Flux and Protein Permeation. Foods 2019, 8, 180. [CrossRef] [PubMed] 